\title{
Modular Organization of Excitatory Circuits between Neurons of the Spinal Superficial Dorsal Horn (Laminae I and II)
}

\author{
Yan Lu and Edward R. Perl \\ Department of Cell and Molecular Physiology, University of North Carolina, Chapel Hill, Chapel Hill, North Carolina 27599
}

\begin{abstract}
Neural circuitry of the spinal superficial dorsal horn (SDH) (laminae I and II) and its relationship to pain and other somatosensory phenomena remain poorly understood. To gain information on this issue, synaptic connections between identified SDH neurons were studied in rat spinal cord slices by simultaneous whole-cell recordings from pairs of cells. Both excitatory and inhibitory connections were noted. This report focuses on the observed excitatory linkages. Synaptic excitatory connections between SDH neurons proved highly selective and consistently were unidirectional. Two patterns repeatedly appeared (for neuron classification, see Materials and Methods) (Grudt and Perl, 2002). Lamina II central neurons, with dorsal root (DR) C-fiber input, monosynaptically excited lamina II vertical neurons with DR A $\delta$ input. Lamina II outer vertical neurons with DR A $\delta$ input monosynaptically excited lamina I neurons. Some of the postsynaptic lamina I cells were shown to project rostrally. In contrast to the usual case for connected neurons, in unconnected pairs, primary afferent input to the same type of neuron proved closely similar. Together, these observations indicate that the neural circuitry in the SDH, including its substantia gelatinosa (lamina II), has an explicit organization in which particular combinations of neurons comprise modules arranged to modify and transmit sensory information arriving from $\mathrm{A} \delta$ and $\mathrm{C}$ primary afferent fibers.
\end{abstract}

Key words: substantia gelatinosa; marginal zone; connected neurons; neural circuits; pain; dorsal horn

\section{Introduction}

Thinly myelinated and unmyelinated primary afferent fibers transmit signals related to nociception, pain, temperature sense, and other somatosensory functions (Perl, 1984, 1992). The superficial dorsal horn (SDH) (laminae I and II) receives a heavy synaptic input from such fibers (Réthelyi and Szentágothai, 1969; Light and Perl, 1979a,b). Classical morphological and modern electrophysiological investigations agree that the SDH is comprised of a variety of neurons embedded in a complex neuropil (Earle, 1952; Pearson, 1952; Réthelyi and Szentágothai, 1969; Ramon y Cajal, 1999; Grudt and Perl, 2002); however, the functional organization of this region remains essentially a mystery. It is known that lamina I, the marginal zone, contains neurons contributing to the spinoreticular and spinothalamic projections that are implicated in processing information important for pain and temperature senses (Kuru, 1949; Perl, 1984; Craig and Kniffki, 1985; Craig, 1994; Han et al., 1998; Ikeda et al., 2003). The subjacent lamina II includes several types of neurons in two divisions, an outer $\left(\mathrm{II}_{\mathrm{o}}\right)$ and inner $\left(\mathrm{II}_{\mathrm{i}}\right)$, distinguished by characteristics of the constituent neurons and features of the primary

Received Jan. 10, 2005; revised March 4, 2005; accepted March 5, 2005.

This work was supported by Research Grant NS-10321 from the National Institute of Neurological Disorders and Stroke of the National Institutes of Health. We thank Kirk McNaughton for excellent histological assistance and Sherry Joseph for substantial aid in preparation of this manuscript.

Correspondence should be addressed to Edward R. Perl, Department of Cell and Molecular Physiology, University of North Carolina, Chapel Hill, 5109 Neuroscience Research Building Campus Box 7545, Chapel Hill, NC 27599. E-mail: erp@med.unc.edu.

DOI:10.1523/JNEUROSCI.0102-05.2005

Copyright $\odot 2005$ Society for Neuroscience $\quad 0270-6474 / 05 / 253900-\bullet \$ 15.00 / 0$ afferent projection (Rexed, 1952; Woodbury et al., 2000). Neurons of lamina II have been argued to participate principally in local circuitry, to a large extent within the SDH itself (Pearson, 1952; Szentágothai, 1964; Réthelyi and Szentágothai, 1969; Light, 1992).

Functioning of a neural system eventually depends heavily on the nature of connections between cells that form its intrinsic circuitry. To establish ways in which its constituent neurons are functionally linked, the present experiments identified synaptic connections between SDH neurons by simultaneous whole-cell recordings from pairs of neurons. Activity in one neuron of a pair was related to evoked responses in the other. We present evidence that particular types of SDH neurons are specifically linked. Both excitatory and inhibitory connections exist. This report focuses on excitatory linkages. We have described inhibitory connections previously (Lu and Perl, 2003). Our observations suggest that the SDH is organized into neuronal modules with selective connections between component cells arranged to amplify, modulate, or integrate primary afferent input.

\section{Materials and Methods}

The Institutional Animal Care and Use Committee of the University of North Carolina, Chapel Hill approved all procedures on living animals. Details of the techniques have been published previously (Lu and Perl, 2003). Briefly, all terminal experiments were performed on young adult Sprague Dawley rats (6-10 weeks postpartum), deeply anesthetized with urethane $(1.5 \mathrm{~g} / \mathrm{kg}$, i.p.). After a lumbosacral laminectomy and removal of the lumbosacral spinal cord with dorsal roots (DRs), the animal was killed with an overdose (intravenous) of pentobarbital. A vibrating mic- 
a
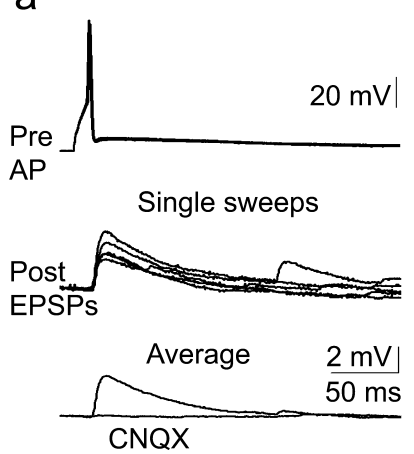

b
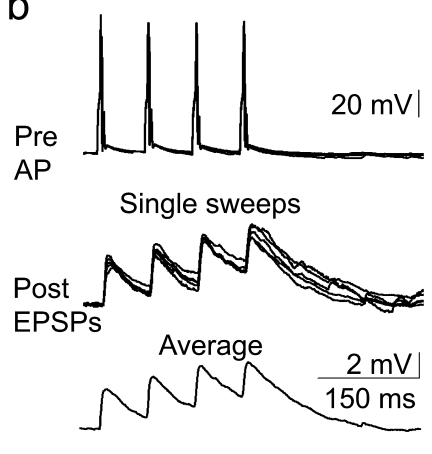

Figure 1. Examples of monosynaptic excitatory connections between SDH neurons. $\boldsymbol{a}$, Lamina II transient central cell projection to lamina II vertical neuron. $\boldsymbol{b}$, Lamina II vertical cell projecting to a lamina I neuron. Top traces, Five superimposed traces from the presynaptic neuron showing action potentials (Pre AP) initiated by depolarization pulses repeating at 0.2 $\mathrm{Hz}$. Middle traces, Five traces of simultaneous recordings of EPSPs from the postsynaptic neuron (Post EPSPs). Bottom traces, Average of 50 successive EPSPs. A block of EPSPs by bath-applied CNQX $(20 \mu \mathrm{m})$ is shown. The latencies from the peak of the presynaptic APs to onset of the EPSPs remain constant at $0.2 \mathrm{~Hz}(\boldsymbol{a})$ and in four repetitions at $70 \mathrm{~ms}$ intervals $(\boldsymbol{b})$. The holding potential was $-60 \mathrm{mV}$ for both presynaptic and postsynaptic neurons.

rotome was used to prepare either transverse $(600-800 \mu \mathrm{m}$ thick) or sagittal (400-600 $\mu \mathrm{m}$ thick) slices from the lumbar spinal cord with an attached segmental dorsal root. After preparation, spinal cord slices were maintained at room temperature $\left(22-25^{\circ} \mathrm{C}\right)$ in standard artificial CSF equilibrated with $95 \% \mathrm{O}_{2}$ and $5 \% \mathrm{CO}_{2}$ [containing the following (in mM): $125 \mathrm{NaCl}, 2.5 \mathrm{KCl}, 2 \mathrm{CaCl}_{2}, 1 \mathrm{MgCl}_{2}, 1.25 \mathrm{NaH}_{2} \mathrm{PO}_{4}, 26 \mathrm{NaHCO}_{3}$, and 25 D-glucose].

To identify projection neurons, some rats were anesthetized with ketamine $(30 \mathrm{mg} / \mathrm{kg})$ and xylazine $(10 \mathrm{mg} / \mathrm{kg})$, supplemented as necessary to produce deep surgical anesthesia. Under sterile conditions, a partial laminectomy was performed at the thoracic 2 level, the dura opened, and the spinal cord hemisected transversely with a fine blade. Gelform soaked in $2 \%$ Fluoro-Gold (FG) was inserted between the cut ends of the hemisected spinal cord. The wound was closed in layers with absorbable suture. One to 2 weeks later, spinal cord slices were prepared as above. FG-labeled neurons in the lumbar cord were located mainly in contralateral lamina I and the deep dorsal horn (laminae IV to VI). Lamina II neurons were not labeled (data not shown).

The electrophysiological recording procedures, labeling, and identification of neuronal types are described in previous publications from this laboratory (Grudt and Perl, 2002; Lu and Perl, 2003). The majority of experiments were performed on sagittal slices that usually had a greater proportion of viable neurons on the slice cut surface than were present in transverse slices. The frequency of synaptic linkages in paired recordings appeared to reflect the orientation of neurons and their relationship to the cut surfaces of the slice. Slices were viewed in visible light and by infrared or ultraviolet illumination. Tight-seal, whole-cell recordings were obtained simultaneously from two SDH neurons using infrared guidance (visualized by a CCD camera fitted to the compound upright microscope). Recordings were made at room temperature $\left(23-25^{\circ} \mathrm{C}\right.$ ). Careful note was made of the locus of each recorded cell relative to landmarks on the slice. Epifluorescence was used to identify FGcontaining neurons in slices from animals with FG labeling. Only one pair of neurons was studied in a slice.

Afferent volleys from the segmental dorsal root were initiated by graduated $0.1-0.5 \mathrm{~ms}$ electrical pulses applied through a suction electrode. In current clamp, the firing pattern of each neuron was determined to $1 \mathrm{~s}$ depolarizing pulses from the holding potential of $-60 \mathrm{mV}(-60$ to -20 $\mathrm{mV})$. Each neuron of a simultaneously recorded pair was stimulated with $10 \mathrm{~ms}$ rectangular $0.1-20 \mathrm{~Hz}$ current pulses to generate action potentials in the search for synaptically evoked responses in the other cell. The receiving neuron (postsynaptic) was tested at its resting potential and in a partially depolarized state $(-35 \mathrm{mV})$. A monosynaptic excitatory connection was presumed if action potentials in the sending (presynaptic)

neuron were followed by fixed-latency, evoked EPSP. The whole-cell recording electrodes contained biocytin $[0.5 \%$ in an internal solution consisting of the following (in $\mathrm{mm}$ ): $130 \mathrm{~K}$-gluconate, $5 \mathrm{KCl}, 4 \mathrm{Mg}$-ATP, 10 phosphocreatine, 0.3 Li-GTP, and 10 HEPES, pH 7.3, $300 \mathrm{mOsm}$ ]. After completion of the electrophysiological observations, the spinal slice was fixed by immersion in a cold solution of $4 \%$ paraformaldehyde/ phosphate buffer for 3-8 d. After cryoprotection, transverse spinal cord slices were sectioned in a cryostat in the parasagittal plane at $60 \mu \mathrm{m}$. Sagittal slices were processed whole. The avidin-biotin complex reaction with a fluorescent label was used to visualize the biocytin-marked cells. Labeled neurons were visualized in a compound microscope fitted with a digital camera and by observation in a confocal microscope. Neural images were reconstructed in three dimensions using the Neurolucida digital computer program (MicroBrightfield, Colchester, VT).

Details of criteria we used to classify SDH neurons were published previously (Grudt and Perl, 2002; Lu and Perl, 2003). Identification of cells mentioned in this report is based on the following. Transient central neurons have somata located in or near the lamina $\mathrm{II}_{\mathrm{o}}-$ lamina $\mathrm{II}_{\mathrm{i}}$ junction, have resting transmembrane potentials (RMPs) of -50 to $-60 \mathrm{mV}$, discharge promptly but briefly to maintained step depolarization, lack $I_{\mathrm{A}}$ current, exhibit a relatively low frequency $(<1 \mathrm{~Hz})$ of background miniature EPSCs (mEPSCs), receive monosynaptic DR C-fiber input, and have dendritic arbors distributed principally rostrocaudally for 150-275 $\mu \mathrm{m}$ with only small dorsoventral and mediolateral extensions. Vertical neurons have soma in lamina II and are distinguished by the following: frequent mEPSCs $(5-7 \mathrm{~Hz})$, a delayed discharge of action potentials to step depolarization, a monosynaptic DR input from A $\delta$ fibers, and dendrites extensively distributed dorsoventrally $(150-200 \mu \mathrm{m})$ as well as rostrocaudally. Lamina I neurons have a soma in lamina I that is distinctly larger than adjacent lamina II cells, dendrites distributed extensively rostrocaudally and mediolaterally in the lamina I-II interface partially capping the SDH, a monosynaptic DR C-fiber input (in some instances $\mathrm{A} \delta$ as well), and show a gap or persisting discharge to maintained depolarization. Islet neurons have a relatively large soma often located near the center of lamina II, have an RMP usually less than -50 $\mathrm{mV}$, give a tonic discharge to maintained depolarization, receive monosynaptic input from DR C fibers, and are characterized by an extended $(>400 \mu \mathrm{m})$, often dense, dendritic arborization oriented rostrocaudally.

Numerical data are presented as the mean \pm SD. Two-sample Student's $t$ test was used to estimate the possibility that differences in values could have occurred by chance ( $p<0.05$ was considered significant). Chemical materials and the pharmacological agents 6-cyano-7 nitroquinoxaline-2,3 dione (CNQX), tetrodotoxin (TTX), and substance P (SP) were obtained from Sigma (St. Louis, MO).

\section{Results}

Simultaneous recordings were made from over 400 pairs of SDH neurons. Although no attempt was made to obtain a true random selection of neuronal types, the varieties of cell types observed in this sample of neurons were consistent with those found in previous studies (Grudt and Perl, 2002; Lu and Perl, 2003). Morphological and electrophysiological details were sufficiently complete to allow identification of 83 of the recordings as being from transient central cells, 43 from tonic central cells, 64 from islet cells, 42 from radial cells, 89 from vertical cells, 16 from lamina I projection cells, and 29 from other lamina I cells (not proven to be projection neurons).

A pair of neurons was considered to be synaptically linked if an action potential in one neuron repeatedly evoked a postsynaptic current or postsynaptic potential in the other. The connection between neurons was judged to be monosynaptic if the latency between the peak of the action potential in the presynaptic cell and the initiation of the postsynaptic potential or current varied $<0.2 \mathrm{~ms}$ in successive observations. Connections between neurons of a pair were judged excitatory when the presynaptic action potential evoked inward current or depolarization at the postsynaptic resting membrane potential. Inhibitory linkages ex- 
hibited evoked outward currents or hyperpolarization (in the partially depolarized state, -35 to $-50 \mathrm{mV}$ ) in response to presynaptic action potentials.

An example of an excitatory fast synaptic connection between neurons is shown in Figure 1. The AMPA glutamate receptor antagonist CNQX (20 $\mu \mathrm{M})$ essentially blocked the evoked EPSP (Fig. 1a, bottom). Inhibitory connections between pairs of neurons in this region of the spinal cord were usually suppressed by bicuculline or rarely by strychnine (Lu and Perl, 2003).

Approximately $10 \%$ of the simultaneously recorded pairs of neurons exhibited one of these types of rapid synaptic connection. This relative rarity makes it clear that connections between neurons in this part of the spinal cord are limited and selective. Twenty-seven of 44 connected pairs were excitatory; they form the subject of this report.

\section{Features of excitatory connections}

In 27 pairs, an action potential in one cell evoked a prompt, near-constant latency EPSP (or EPSC) in the other. At a postsynaptic holding potential of $-60 \mathrm{mV}$, the evoked potential was depolarizing (inward current) and had a near-constant latency between the peak of the presynaptic action potentials and the onset of postsynaptic responses. This was interpreted as indicative of a monosynaptic connection (Yoshimura and Jessell, 1989; Li and Perl, 1995; Lu and Perl, 2003). These prompt evoked EPSPs reversed polarity when the transmembrane potential of the postsynaptic cell was held near $0 \mathrm{mV}$ (data not shown). In every case $(n=16)$, the AMPA glutamate receptor antagonist CNQX (20 $\mu \mathrm{M})$ essentially blocked the evoked postsynaptic response (Fig. 1a).

The latency between the presynaptic action potential peak and the initiation of the postsynaptic event in different pairs varied between 1.4 and $2.1 \mathrm{~ms}$. At a postsynaptic holding potential of -60 $\mathrm{mV}$, the individual evoked EPSPs ranged in amplitude from 0.9 to $2.6 \mathrm{mV}$. The time to peak for evoked EPSPs varied from 7.9 to $12.4 \mathrm{~ms}$, and the half-decay time ranged from 29.9 to $43.2 \mathrm{~ms}(n=27)$. EPSPs evoked by a succession of presynaptic action potentials at holding potentials of $-60 \mathrm{mV}$, typically summated (Fig. 1b). These features for the 27 excitatory connections between pairs of SDH neurons are consistent with synapses involving glutamate activation of an AMPA postsynaptic receptor (Honoré et al., 1988).

Excitatory connections between pairs of neurons were always unidirectional. Action potentials in a neuron found to be postsynaptic never evoked responses in the neuron presynaptic to it. Of the 27 pairs exhibiting excitatory linkages, 20 were between neurons both of which were located in lamina II. Seven b
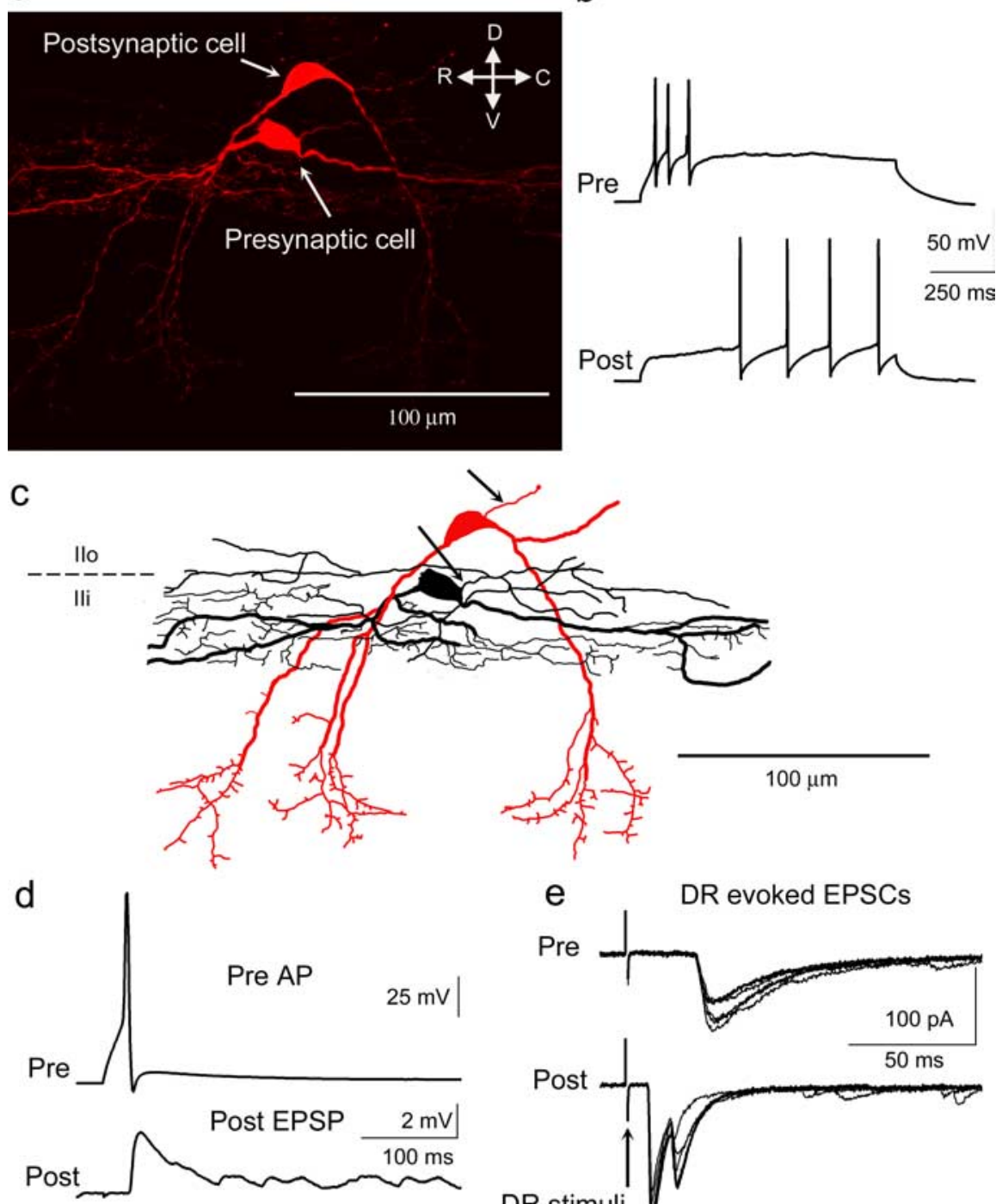

e DR evoked EPSCs

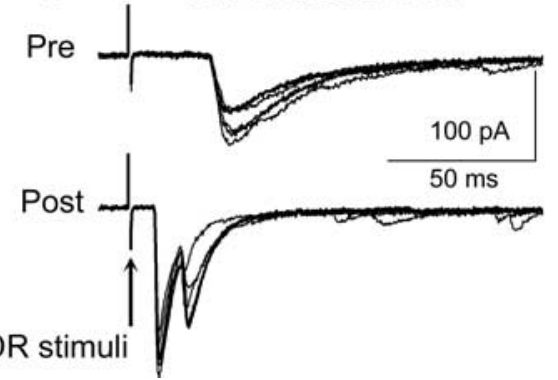

DR stimuli

Figure 2. Monosynaptic excitatory connection between a lamina II transient central neuron and a lamina II vertical neuron. $\boldsymbol{a}$ Maximum projection confocal images of the biocytin-labeled connected neurons. Presynaptic, Lamina II transient central cell; neurons showing the presynaptic central cell in black and the postsynaptic vertical cell in red. Arrows indicate putative axons. Dotted lines mark approximate borders between dorsal horn laminae. $\boldsymbol{d}$, Simultaneous whole-cell recordings illustrating the cells). $\boldsymbol{e}$, Simultaneous whole-cell recordings from the two neurons showing monosynaptic EPSCs evoked by dorsal root stimulainput, whereas the lamina II vertical cell shows responses evoked by DR A $\delta$ fibers. C, Caudal; D, dorsal; R, rostral; V, ventral; Pre, presynaptic; Post, postsynaptic; AP, action potential.

connected pairs consisted of lamina II neurons projecting to lamina I neurons. One of the latter represented a connection between a lamina $\mathrm{II}_{\mathrm{i}}$ central type of neuron and a projection lamina I neuron; the other six linked lamina $\mathrm{II}_{\mathrm{o}}$ cells to lamina I neurons.

The 20 lamina II to lamina II excitatory connections represented several categories of neurons; however, 12 pairs exhibited closely consistent morphological and functional features for the presynaptic and postsynaptic elements. Based on criteria used in previous studies (Grudt and Perl, 2002; Lu and Perl, 2003), these 12 pairs represented excitation from transient central cells of lamina $\mathrm{II}_{\mathrm{i}}$ to vertical neurons of lamina $\mathrm{II}_{\mathrm{o}}$. In addition, there was one observation of a transient central cell connecting to a transient central cell. Another instance consisted of a transient central 

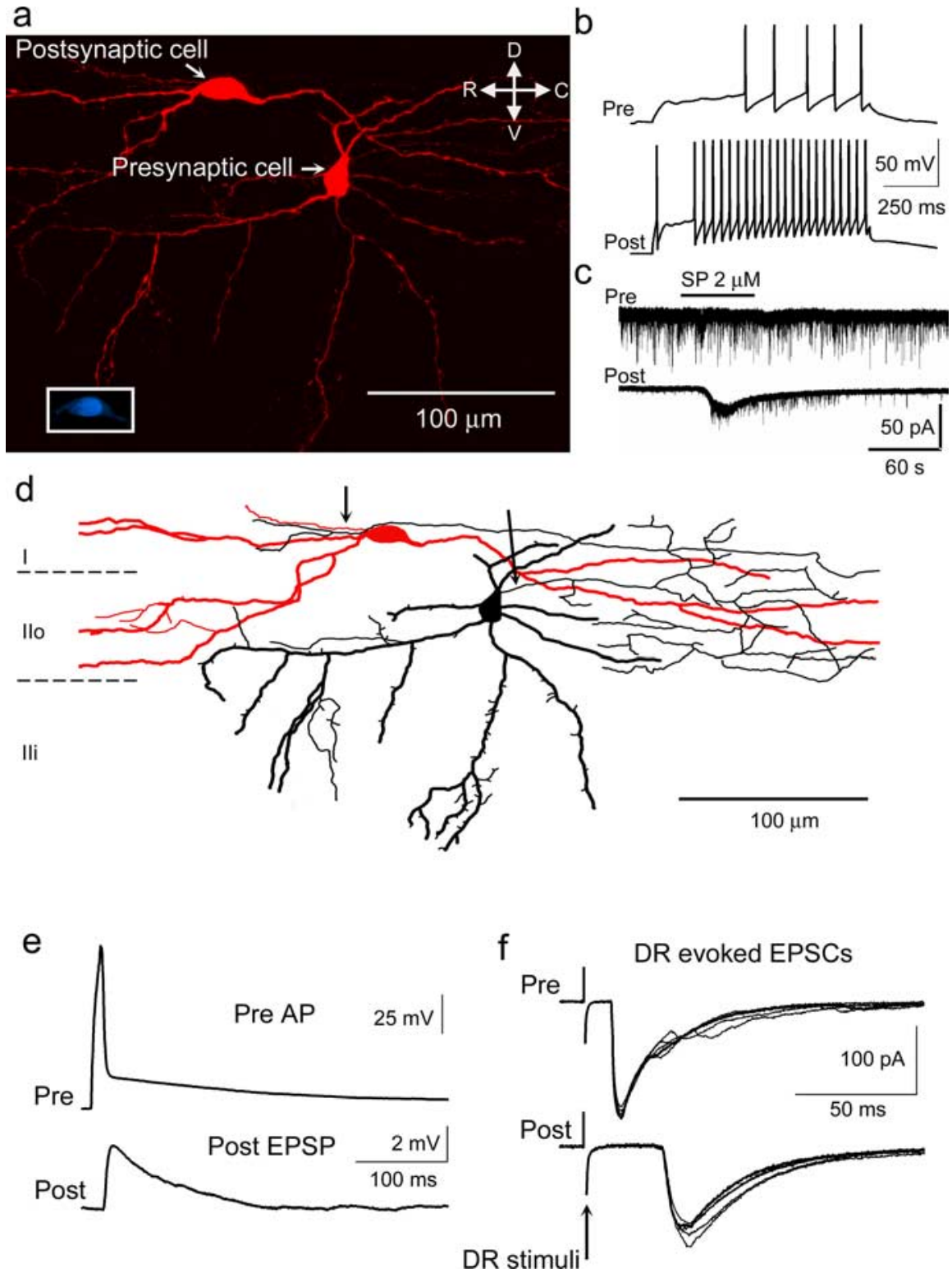

Figure 3. Monosynaptic excitatory connection from a lamina $\|_{0}$ vertical cell to a lamina I projection neuron. $\boldsymbol{a}$, Maximum projection confocal images of the connected cells. Presynaptic, Lamina $I_{0}$ vertical neuron; postsynaptic, lamina I neuron. The bottom left insert shows retrogradely transported FG from the thoracic spinal cord labeling the lamina I cell. $\boldsymbol{b}$, Action potential firing patterns of the connected neurons. c, Simultaneous voltage-clamp recordings showing inward current in the lamina I cell evoked by substance $\mathrm{P}(2 \mu \mathrm{m})$ in the presence of $0.5 \mu \mathrm{m}$ TTX but not in the lamina II vertical cell. $\boldsymbol{d}$, Reconstructions of the labeled neurons depicting the presynaptic lamina $I_{0}$ vertical cell in black and the postsynaptic lamina I cell in red. Arrows indicate putative axons. $\boldsymbol{e}$, Simultaneous current-clamp recordings showing the synaptic connections between two neurons (average of 50 successive traces; membrane potential, $-60 \mathrm{mV}$ for both cells). $\boldsymbol{f}$, Simultaneous voltage-clamp recordings from the pair showing monosynaptic EPSCs evoked by dorsal root stimulation (holding potential, $-60 \mathrm{mV}$ for both cells). Five trials are superimposed. The vertical cell has a monosynaptic dorsal root $A \delta$-fiber input; the lamina I projection cell receives monosynaptic DR C-fiber connections. C, Caudal; D, dorsal; R, rostral; V, ventral; Pre, presynaptic; Post, postsynaptic; AP, action potential.

cell connecting to a tonic central cell. The biocytin staining was inadequate for proper identification of the cell morphology to classify six pairs of connected lamina II neurons. The following describes connection patterns observed more than once.

\section{Connections between lamina $\mathrm{II}_{\mathrm{i}}$ transient central cells and} lamina $\mathrm{II}_{\mathrm{o}}$ vertical neurons

In the linkage between lamina $\mathrm{II}_{\mathrm{i}}$ transient central and lamina $\mathrm{II}_{\mathrm{o}}$ vertical neurons, the RMP of the two cells were similar: $-58.6 \pm$ $2.8 \mathrm{mV}$ presynaptic and $-60.2 \pm 3.0 \mathrm{mV}$ postsynaptic $(p>$
0.05). On the other hand, the connected neurons differed in their discharge of action potentials to graded depolarizing steps as shown in Figure $2 b$. At step depolarizations of $10-40 \mathrm{mV}$ from a holding potential of $-60 \mathrm{mV}$, the presynaptic neurons consistently fired a relatively short burst of impulses followed by silence for the remaining depolarization. In contrast, the postsynaptic neurons usually only discharged after a delay from the onset of depolarization $(n=12)$. In the instances in which both neurons were well marked by biocytin (6 of 12), the presynaptic cell had a consistently smaller somata than the postsynaptic neuron (Fig. 2a,c). The largest dimension of presynaptic somata averaged $14.7 \pm 0.6 \mu \mathrm{m}(n=6)$, whereas that of the postsynaptic somata was $17.6 \pm 1.2$ $\mu \mathrm{m}(n=8 ; p<0.05)$. The principal dendritic expansions of the presynaptic neurons $(n=6)$ were oriented rostrocaudally $(236.7 \pm 40.5 \mu \mathrm{m})$ with much smaller arborization in the mediolateral and dorsoventral $(45.3 \pm 5.7 \mu \mathrm{m})$ directions. In distinction, the postsynaptic neurons $(n=8)$ had a substantially greater dendritic expansion in the dorsoventral direction $(154.9 \pm 13.0 \mu \mathrm{m})(p<0.05)$, as depicted in Figure 2. The rostrocaudal dendritic extensions of the presynaptic and postsynaptic neurons $(212.1 \pm 27.6 \mu \mathrm{m})$ were similar.

When noted, a thin, uniform-diameter process originating from the somata or proximal dendrite was presumed to be the axon of the cell (Fig. 2a,c). Such axon-like processes of the presynaptic neurons passed close to the dendritic processes of the postsynaptic cell; however, morphological identification of synaptic junctions in light microscopic material is at best uncertain. The axon-like processes of the presynaptic neuron generally branched and distributed partially within the dendritic field of the parent neuron and then were lost from view, possibly because of pruning in the preparation of histological sections. Axon-like neurites of the postsynaptic cells usually had processes distributed to lamina $\mathrm{I}$ and often a branch passing deep to lamina $\mathrm{II}_{\mathrm{o}}$.

In a substantial sample of lamina II neurons, only the type labeled as transient central neurons exhibited transient firing to maintained depolarizing current (Grudt and Perl, 2002; Lu and Perl, 2003). Furthermore, only neurons with extensive vertically directed dendrites fired after a delay to a depolarizing step (Grudt and Perl, 2002). Together, the physiological and morphological features of the presynaptic and postsynaptic neurons in the 12 examples of connected neurons closely fit those of lamina II neuronal types identified previously (Grudt and Perl, 2002). The presynaptic cells regularly exhibited 
a transient pattern of action potential generation, lack of $I_{\mathrm{A}}$, somata location, and dendritic spread typical for the transient (non- $I_{\mathrm{A}}$ ) central type of neurons. The postsynaptic neurons showed the delayed discharge pattern, somata location, somata size, and exceptional dorsal-ventral dendritic spread characteristic of lamina $\mathrm{II}_{\mathrm{o}}$ vertical cells.

Primary afferent volleys, initiated by stimulation of the segmental dorsal root with brief electrical pulses, evoked EPSCs or EPSPs in both neurons of eight of the 12 connected lamina II pairs. The stability of latency on repeated trials (Fig. 2e) suggested that such DR-evoked responses were mediated monosynaptically. The estimated conduction velocity $(\mathrm{CV})$ of the DR projection to transient central cells was $0.3 \pm 0.03 \mathrm{~m} / \mathrm{s}$. This DR CV is in keeping with rodent $\mathrm{C}$ fibers at $22-25^{\circ} \mathrm{C}$ (Lynn and Carpenter, 1982; Lawson et al., 1997). The DR CV for the response evoked in the postsynaptic vertical cells was $1.14 \pm 0.1$ $\mathrm{m} / \mathrm{s}(n=7)$; this value is in the range of rodent $\mathrm{A} \delta \mathrm{DR}$ fibers.

Connections between lamina $\mathrm{II}_{\mathrm{o}}$ vertical cells and lamina I neurons

In seven instances, a neuron located in lamina II made an excitatory connection to one in lamina I. In six of these seven, the presynaptic neuron had characteristics of a lamina II $_{\mathrm{o}}$ vertical cell, closely comparable with those of the postsynaptic cell in the transient central-to-vertical cell pattern described above. The six presynaptic neurons of the $\mathrm{II}_{\mathrm{o}}$ to lamina I linkage showed a delayed discharge to depolarizing steps $(n=6)$ (Figs. $3 b, 4 b)$. The somata size of the lamina $\mathrm{II}_{\mathrm{o}}$ neurons averaged $17.4 \pm 3.5$ $\mu \mathrm{m}$, and their dorsal-ventral dendritic arborization extended $171.1 \pm 17.2 \mu \mathrm{m}$ (Figs. $3 a, d, 4 a, c$ ), dimensions that overlapped those of the postsynaptic vertical cells of the transient central-to-vertical neuron connection (see above). The CV of the dorsal-root input to the presynaptic lamina $\mathrm{II}_{\mathrm{o}}$ neurons averaged $1.2 \pm 0.1 \mathrm{~m} / \mathrm{s}$, also equivalent to DR A $\delta$ CVs for the postsynaptic vertical cells in the transient-to-vertical neuron connection. Projection of a vertical type of lamina II neuron to a lamina I neuron has been suggested before on circumstantial morphological and physiological grounds (Gobel, 1978; Bennett et al., 1980; Gobel et al., 1980; Ramon y Cajal, 1999). The present evidence represents the first proven demonstration of functional connections between these cell types.

The receiving (postsynaptic) lamina I neurons in the projection from lamina $\mathrm{II}_{\mathrm{o}}$ vertical neurons fell into two categories. Three of the six lamina I neurons receiving vertical neuron excitation had inward currents evoked by SP $(2 \mu \mathrm{M}$ in the superfusion solution) in the presence of TTX $(0.5 \mu \mathrm{M})$. The simultaneously

d b
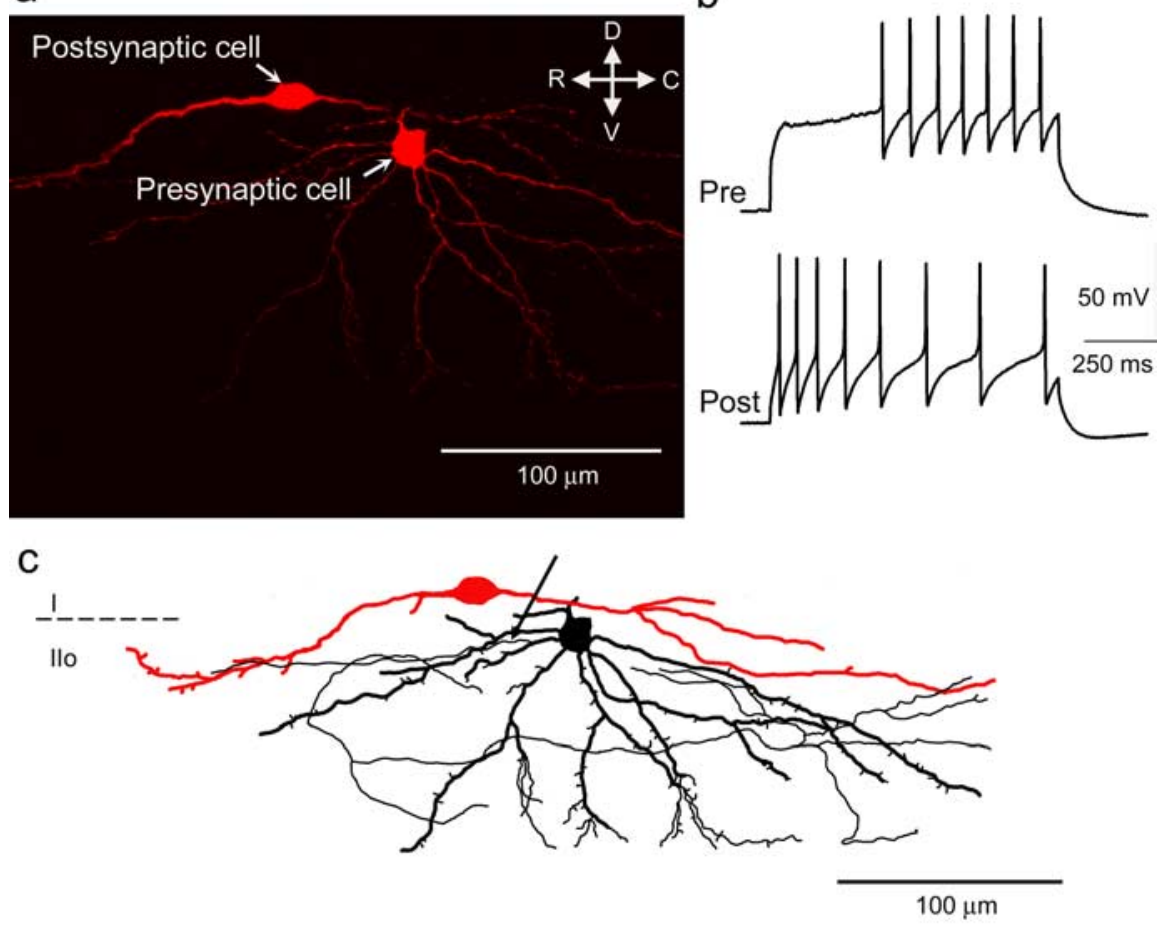

Figure 4. Monosynaptic excitatory linkage from a lamina $\|_{0}$ vertical cell to a lamina I, substance P-insensitive neuron. $\boldsymbol{a}$, Maximum projection confocal images of the connected cells. Presynaptic, Lamina $\|_{0}$ vertical cell. Postsynaptic, Lamina I neuron. b. Action potential firing patterns of the connected neurons. $\boldsymbol{c}$, Reconstructions of the labeled neurons showing the presynaptic recording showing the synaptic connection (average of 50 successive traces; membrane potential, $-60 \mathrm{mV}$ for both cells). $\boldsymbol{e}_{\text {, }}$ potential, $-60 \mathrm{mV}$ for both cells). Five trials are superimposed. The vertical neuron receives monosynaptic DR A $\delta$ input, whereas the lamina I, substance $P$-insensitive neuron shows both monosynaptic $A \delta$ - and C-fiber DR input. C, Caudal; D, dorsal; R, rostral; V, ventral; Pre, presynaptic; Post, postsynaptic; AP, action potential.

recorded lamina $\mathrm{II}_{\mathrm{o}}$ (presynaptic) neurons were not affected by SP (Fig. 3c). Most lamina I, long-projection neurons possess SP receptors; however, whether all SP-responsive lamina I neurons project rostrally is uncertain (Todd et al., 2002). In two of our vertical cell-to-lamina I connections, the lamina I neuron was labeled by FG applied to the thoracic spinal cord and responded to SP with inward current (Fig. 3a,c). These two lamina I neurons were considered to be long-projection neurons.

Three lamina I neurons receiving input from lamina $\mathrm{II}_{\mathrm{o}}$ vertical neurons were unresponsive to SP and differed from the putative projection category by their response to depolarizing steps. All three of the SP-responsive, connected lamina I neurons discharged in a gap-firing pattern, a feature that has been reported to 
a
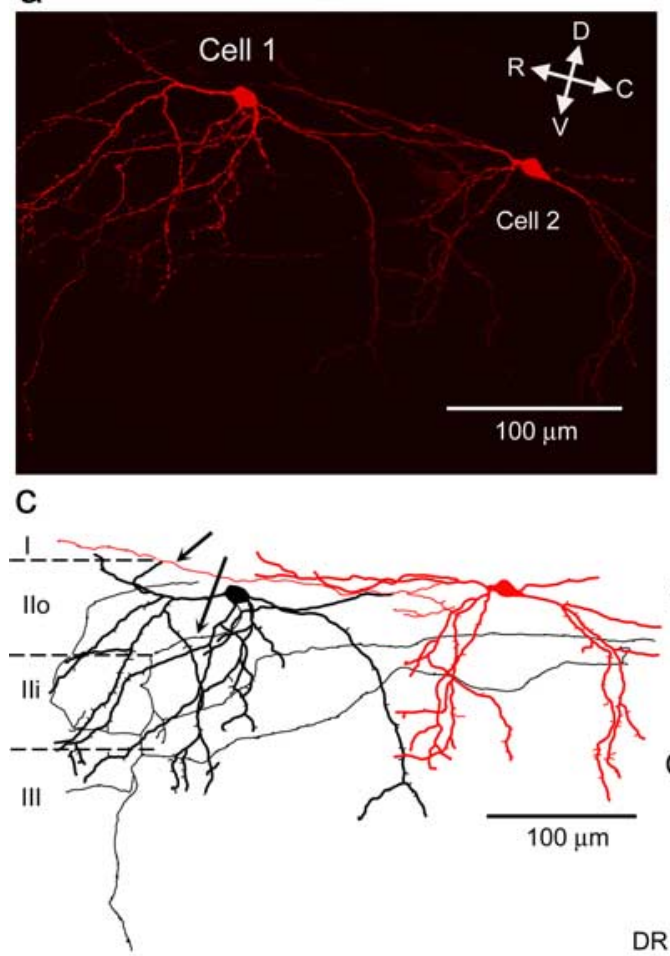

Figure 5. Simultaneously recorded, unconnected lamina II vertical neurons receiving closely similar DR A $\delta$-fiber input. $\boldsymbol{a}$, Maximum projection confocal image of the two biocytin-labeled neurons. $\boldsymbol{b}$, Action potential firing patterns of the two vertical neurons. $\boldsymbol{c}$, Reconstructions of labeled neurons: one vertical cell is black, and the other is red. Arrows indicate putative axons. $\boldsymbol{d}$, Simultaneous voltage-clamp recordings showing monosynaptic EPSCs evoked by dorsal root stimulation (holding potential, -60 $\mathrm{mV}$ for each (ell). Five trials are superimposed. Both cells receive monosynaptic excitatory input from dorsal root $A \delta$ fibers with the same or similar thresholds. Note the identical latencies and threshold stimulus intensities for the two cells. C, Caudal; D, dorsal; R, rostral; V, ventral.

characterize spinobrachial and spino-periaqueductal gray neurons projecting from lamina I (Ruscheweyh et al., 2004). In contrast, the SP-insensitive lamina I neurons of the connected pairs discharged without a gap, showing progressive lengthening of intervals between action potentials with maintained depolarization (Fig. 4b).

The postsynaptic lamina I cells in five of the six lamina $\mathrm{II}_{\mathrm{o}}$-tolamina I connected pairs were well marked by biocytin. The two proven lamina I projection neurons had the largest somata of the observed SDH cells $(25.2,27.1 \mu \mathrm{m})$ (Fig. 3a). The somata of two SP-insensitive, unproven projection lamina I neurons were 22.5 and $19.2 \mu \mathrm{m}$ in diameter (Fig. $4 a, c$ ). The dendritic arborizations of the proven projection SP-responsive lamina I neurons $(n=2)$ in the rostrocaudal dimension were 590.9 and $685.4 \mu \mathrm{m}$. These latter two neurons were flattened dorsoventrally with dendritic extensions in that dimension measuring 56.9 and $68.3 \mu \mathrm{m}$. The SP-responsive lamina I-connected cell that was not proven to project rostrally had a soma $23.6 \mu \mathrm{m}$ in diameter and a rostrocaudal dendritic extent of $490.3 \mu \mathrm{m}$. The two well stained, SPinsensitive lamina I cells had smaller rostrocaudal dendritic extensions $(340.2,320.1 \mu \mathrm{m})$, although the dorsoventral expansion $(39.6,64.2 \mu \mathrm{m})$ was similar to the putative projection cells.

Presumed axon-like neurites of the SP-responsive lamina I neurons originated from their somata or a proximal dendrite (Fig. $3 a, d$ ) and in two instances were ventrally directed. Axon-like neurites of two SP-unresponsive lamina I neurons were not identified.

DR stimulation evoked monosynaptic C-fiber (estimated CV,
0.33-0.38 $\mathrm{m} / \mathrm{s}$ ) EPSCs in the two SPresponsive, proven lamina I projection neurons (Fig. 3f). The SP-responsive, unproven projection neuron had a DR A $\delta$ fiber $(0.89 \mathrm{~m} / \mathrm{s})$-evoked monosynaptic EPSC. Monosynaptic C-fiber (0.37, 0.35, $0.37 \mathrm{~m} / \mathrm{s}$ ) EPSCs were evoked in three SPinsensitive lamina I cells. One of the latter also had a DR A $\delta$-fiber input $(\mathrm{CV}, 1.7$ $\mathrm{m} / \mathrm{s}$ ), illustrated in Figure $4 e$.

\section{Parallel dorsal root input to equivalent SDH neurons}

The repetition of particular patterns of neural connectivity intimates that given types of neurons in equivalent circuits play functionally similar parts. Supporting this concept, we noted unconnected identical types of neurons to have notably parallel DR-evoked responses. Seven pairs of simultaneously recorded vertical cells were found to receive input from the same or closely similar dorsal-root A $\delta$ fibers. In the example shown in Figure 5, at a DR stimulus intensity of $1.2 \mathrm{~V}$ ( $0.1 \mathrm{~ms}$ pulses $)$, neither cell responded. When the DR stimulus intensity was slightly increased to $1.3 \mathrm{~V}$, evoked EPSCs appeared at the same latencies ( $8.1 \mathrm{~ms}$ ) (Fig. $5 d$ ) in both vertical neurons. The estimated conduction velocity of the DR afferent fibers evoking EPSPs in seven unconnected vertical cell pairs was $1.2 \pm 0.1 \mathrm{~m} / \mathrm{s}$. Closely similar thresholds for DR-evoked responses implies that the same category of primary-afferent $A \delta$ fibers project to different vertical neurons.

An equivalent situation was evident in unconnected pairs of transient central cells. The DR input to these central cells came from $C$ fibers. For seven unconnected transient central pairs, the estimated DR CV was $0.31 \pm 0.02 \mathrm{~m} / \mathrm{s}$. In the example shown in Figure 6, at an intensity of $4.2 \mathrm{~V}(0.5 \mathrm{~ms}$ pulse duration), neither cell exhibited an evoked postsynaptic response. When the stimulus intensity was increased by a small amount $(4.3 \mathrm{~V})$, evoked EPSCs at the same latencies appeared simultaneously in both neurons (Fig. 6d). These observations offer circumstantial evidence that the afferent connections from the dorsal roots are organized selectively according to SDH neuronal type.

\section{Discussion}

Figure 7 diagrams SDH circuitry derived from the present observations. In summary, certain transient central neurons of lamina $\mathrm{II}_{\mathrm{i}}$ that receive a dorsal root $\mathrm{C}$-fiber input have AMPA receptormediated excitatory synaptic projections to vertical cells of lamina $\mathrm{II}_{\mathrm{o}}$. Vertical neurons of lamina $\mathrm{II}_{\mathrm{o}}$, principally recipients of a DR-A $\delta$ input, make AMPA-receptor excitatory contacts with both projection and nonprojection lamina I neurons. The lamina I cells receive a direct DR C-fiber input. The central synapses of the primary afferent (DR) A $\delta$ and $C$ fibers also involve mediation by AMPA glutamate receptors. It is important to note that this diagram is not meant to imply that all transient central or vertical neurons make the connections outlined. Observations on other connected neurons and their axon trajectories indicate that the 
patterns depicted are only a part of the neural circuitry in the rodent SDH.

The present results make it clear that connections between neurons of the SDH are explicit and selective. Thus, spinal mechanisms involved in at least some functions the SDH serves are associated with a specific pattern of neural wiring. Neurons lying in close proximity to one another with axons passing near to dendritic extensions of a different cell infrequently evidence fast synaptic linkage. On the other hand, particular combinations of neurons are found repeatedly to be connected. The latter is suggestive of a modular organization in which specified combinations of neurons serve a common function. Modular structure is hardly surprising, because throughout the mammalian CNS, repeating patterns of neuronal connections have been long noted (Lorente de No, 1938; Mountcastle, 1957; Leise, 1990). The connectivity uncovered in the present work supports the concept that SDH neurons are linked by excitatory synaptic connections in which a type of neuron participates in a circuit module in a recurring way.

It seems reasonable to postulate this modular connectivity relates to the primary afferent projection. There is a high density of primary afferent synaptic contacts in the region (Ranson, 1914; Szentágothai, 1964; Light and Perl, 1979a; Perl, 1984). The neurons in excitatory connections we describe consistently receive strong primary afferent input. The net effect of the forward feeding of information by the excitatory connections would be to mix the primary afferent input impinging on the presynaptic cells with that projecting directly to the postsynaptic elements. Significant in this consideration is the fact that the vertical cells in all three connection patterns that we report here manifest an important input from dorsal root $\mathrm{A} \delta$ fibers, a projection that is missing (or less consistent) directly to lamina I neurons and to transient central cells. In the transient central cell-to-vertical cell excitatory connection, the peripheral $\mathrm{C}$-fiber input to the central cell is conveyed to the vertical neuron. The excitatory linkages of vertical cells, in turn, are in position to transmit signals related to their primary afferent input from DR A $\delta$ fibers to projection and nonprojection neurons of lamina I. The link of vertical cell to lamina I neurons is important because it gives $\mathrm{A} \delta$ input of the vertical cells a path to neurons projecting information rostrally to suprasegmental centers. It also provides a polysynaptic pathway from a subset of peripheral C-fiber sensory units from transient central cells to lamina $\mathrm{II}_{\mathrm{o}}$ vertical cells and thus to lamina I projecting cells. These arrangements appear to provide mechanisms by which the primary afferent input maintains selectivity in connections to CNS neurons while at the same time permitting integration of signals from different peripheral sense organs.

We reported recently results from similar experiments demonstrating a quite different linkage between specific types of lamina $\mathrm{II}_{\mathrm{i}}$ neurons ( $\mathrm{Lu}$ and Perl, 2003). Lamina $\mathrm{II}_{\mathrm{i}}$ islet cells were found to make a bicuculline-sensitive inhibitory connection to b

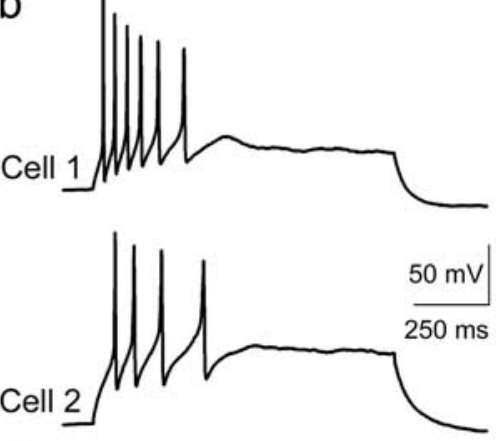

d

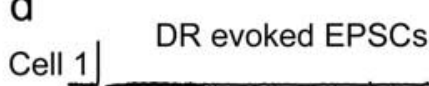

Cell 1$]$ 
lamina $\mathrm{II}_{\mathrm{i}}$ transient central neurons. Furthermore, the primary afferent projection to the presynaptic islet neuron was from notably more rapidly conducting $\mathrm{C}$ fibers than those exciting the postsynaptic transient central cells. It is tempting to try to link these previous and the present observations. One possibility is that the transient central neurons of the islet cell inhibitory pathway may be the same transient central cells that make the excitatory projections to lamina $\mathrm{II}_{\mathrm{o}}$ vertical neurons of the present report. Unfortunately, we have only the characterization of the cell types as evidence. At this point, the range of patterns in which transient central or vertical neurons participate is unknown.

The afferent function of the neurons identified in the present work is an obvious question. Unfortunately, our observations are difficult to relate directly to existing reports of in vivo signaling. Past comprehensive in vivo studies were either done on other species or lack enough information on either morphological or electrophysiological characteristics to permit matching to our classification (Light et al., 1979; Han et al., 1998; Light and Willcockson, 1999). Given the large proportion of nociceptive afferents in the DR $A \delta$ - and C-fiber populations, it is possible to speculate that our patterns of SDH connections are part of mechanisms contributing to nociception and pain. Along this line, three of our lamina I cells that received excitatory projections from lamina II vertical cells did appear morphologically similar to fusiform lamina I neurons that have been proposed as a nociceptive specific class (Han et al.,1998) (but see Todd et al., 2005). On the other hand, significant numbers of low-threshold DR A $\delta$ and DR C mechanoreceptors project to lamina II (Light and Perl, 1979b; Sugiura et al., 1986; Woodbury et al., 2000). Moreover, lamina $\mathrm{II}_{\mathrm{i}}$, in rat and other species, contains "slow brush" neurons that are excited by very light tactile stimuli and do not exhibit nociceptive characteristics (Light et al., 1979; Light and Willcockson, 1999). Therefore, it is also conceivable that our connectivity patterns are parts of multireceptive or innocuous mechanoreceptive mechanisms. Eventual clarification of the relationships between afferent messaging and SDH neuronal connectivity awaits experiments establishing signaling features under conditions compatible with analyses of intrinsic circuitry.

\section{References}

Bennett GJ, Abdelmoumene M, Hayashi H, Dubner R (1980) Physiology and morphology of substantia gelatinosa neurons intracellularly stained with horseradish peroxidase. J Comp Neurol 194:809-827.

Craig AD (1994) Spinal and supraspinal processing of specific pain and temperature. In: Touch, temperature, and pain in health and disease: mechanisms and assessments (Boivie J, Hansson P, Lindblom U, eds), pp 421-437. Seattle: International Association for the Study of Pain.

Craig AD, Kniffki KD (1985) The multiple representation of nociception in the spinothalamic projection of lamina I cells in the cat. In: Development, organization, and processing in somatosensory pathways (Rowe M, Willis W, eds), pp 347-353. New York: Alan R. Liss.

Earle KM (1952) The tract of Lissauer and its possible relation to the pain pathway. J Comp Neurol 96:93-109.

Gobel S (1978) Golgi studies of the neurons in layer II of the dorsal horn of the medulla (trigeminal nucleus caudalis). J Comp Neurol 180:395-414.

Gobel S, Falls WM, Bennett GJ, Abdelmoumene M, Hayashi H, Humphrey E (1980) An EM analysis of the synaptic connections of horseradish peroxidase-filled stalked cells and islet cells in the substantia gelatinosa of adult cat spinal cord. J Comp Neurol 194:781-807.

Grudt TJ, Perl ER (2002) Correlations between neuronal morphology and electrophysiological features in the rodent superficial dorsal horn. J Physiol (Lond) 540:189-207.

Han Z-S, Zhang E-T, Craig AD (1998) Nociceptive and thermoreceptive lamina 1 neurons are anatomically distinct. Nat Neurosci 1:218-225.

Honoré T, Davies SN, Drejer J, Fletcher EJ, Jacobsen P, Lodge D, Nielsen FE (1988) Quinoxalinediones: potent competitive non-NMDA glutamate receptor antagonists. Science 241:701-703.

Ikeda H, Heinke B, Ruscheweyh R, Sandkuhler J (2003) Synaptic plasticity in spinal lamina I projection neurons that mediate hyperalgesia. Science 299:1237-1240.

Kuru M (1949) The sensory paths in the spinal cord and brain stem of man. Resume, pp 3-35. Tokyo: Sogensya.

Lawson SN, Crepps B, Perl ER (1997) Relationship of substance P to afferent characteristics of dorsal root ganglion neurones in guinea-pig. J Physiol (Lond) 505:177-191.

Leise EM (1990) Modular construction of nervous systems: a basic principal of design for invertebrates and vertebrates. Brain Res Brain Res Rev 15:1-23.

Li J, Perl ER (1995) ATP modulation of synaptic transmission in the spinal substantia gelatinosa. J Neurosci 15:3357-3365.

Light AR (1992) The organization of nociceptive neurons in the spinal grey matter. In: The initial processing of pain and its descending control: spinal and trigeminal systems, Chap 6, pp 109-150. Basel: Karger.

Light AR, Perl ER (1979a) Reexamination of the dorsal root projection to the spinal dorsal horn including observations on the differential termination of coarse and fine fibers. J Comp Neurol 186:117-132.

Light AR, Perl ER (1979b) Spinal termination of functionally identified primary afferent neurons with slowly conducting myelinated fibers. J Comp Neurol 186:133-150.

Light AR, Willcockson HH (1999) Spinal laminae I-II neurons in rat recorded in vivo in whole cell, tight seal configuration: properties and opioid responses. J Neurophysiol 82:3316-3326.

Light AR, Trevino DL, Perl ER (1979) Morphological features of functionally defined neurons in the marginal zone and substantia gelatinosa of the spinal dorsal horn. J Comp Neurol 186:151-171.

Lorente de No R (1938) Cerebral cortex: architecture, intracortical connections, motor projections. In: Physiology of the nervous system (Fulton JF, ed), pp 291-339. Oxford: Oxford UP.

Lu Y, Perl ER (2003) A specific inhibitory pathway between substantia gelatinosa neurons receiving direct C-fiber input. J Neurosci 23:8752-8758.

Lynn B, Carpenter SE (1982) Primary afferent units from the hairy skin of the rat hind limb. Brain Res 238:23-43.

Mountcastle VB (1957) Modality and topographic properties of single neurons of cat's somatic sensory cortex. J Neurophysiol 20:408-434.

Pearson AA (1952) Role of gelatinous substance of spinal cord in conduction of pain. Arch Neurol Psychiatry 68:515-529.

Perl ER (1984) Pain and nociception. In: Handbook of physiology. The nervous system, Vol 3 (Darian-Smith I, ed), pp 915-975. Bethesda, MD: American Physiological Society.

Perl ER (1992) Function of dorsal root ganglion neurons: an overview. In: Sensory neurons: diversity, development and plasticity (Scott S, ed), pp 3-23. New York: Oxford.

Ramon y Cajal S (1999) Texture of the nervous system of man and the vertebrates, Vol 1 (Pasik P, Pasik T, translators and eds), pp 287-291, 355-366. Wien, Austria: Springer.

Ranson SW (1914) The tract of Lissauer and the substantia gelatinosa rolandi. Am J Anat 16:97-126.

Réthelyi M, Szentágothai J (1969) The large synaptic complexes of the substantia gelatinosa. Exp Brain Res 7:258-274.

Rexed B (1952) The cytoarchitectonic organization of the spinal cord in the cat. J Comp Neurol 96:415-495.

Ruscheweyh R, Ikeda H, Heinke B, Sandkuhler J (2004) Distinctive membrane and discharge properties of rat spinal lamina I projection neurones in vitro. J Physiol (Lond) 555:527-543.

Sugiura Y, Lee CL, Perl ER (1986) Central projections of identified, unmyelinated afferent fibers innervating mammalian skin. Science 234:358-361.

Szentágothai J (1964) Neuronal and synaptic arrangement in the substantia gelatinosa rolandi. J Comp Neurol 122:219-239.

Todd AJ, Puskar Z, Spike RC, Hughes C, Watt C, Forrest L (2002) Projection neurons in lamina I of rat spinal cord with the neurokinin 1 receptor are selectively innervated by substance p-containing afferents and respond to noxious stimulation. J Neurosci 22:4103-4113.

Todd AJ, Spike RC, Young S, Puskar Z (2005) Fos induction in lamina I projection neurons in response to noxious thermal stimuli. Neuroscience 131:209-217.

Woodbury CJ, Ritter AM, Koerber HR (2000) On the problem of lamination in the superficial dorsal horn of mammals: a reappraisal of the substantia gelatinosa in postnatal life. J Comp Neurol 417:88-102.

Yoshimura M, Jessell TM (1989) Primary afferent-evoked synaptic responses and slow potential generation in rat substantia gelatinosa neurons in vitro. J Neurophysiol 62:96-108. 